\title{
Editorial
}

Die Herausgeber geben bekannt, dass mit dem Jahrgang 2004 Irmhild Saake in die Redaktion eingetreten ist und die Aufgaben der Betreuung von Autorinnen und Autoren und Manuskripten ab sofort gemeinsam mit Markus Schroer wahrnehmen wird.

Die Herausgeber

\section{Geschäftsbericht 2003}

Im Geschäftsjahr 2003 (Oktober 2002 bis Oktober 2003) wurden der Redaktion der Sozialen Welt 58 Manuskripte eingereicht. Nach Überarbeitung angenommen wurden hiervon 24. Abgelehnt wurden 34 Manuskripte. Daraus ergibt sich eine Ablehnungsquote von $59 \%$. Die Entscheidungen der Herausgeber wurden durch 39 auswärtige Fachgutachten unterstützt. 